\title{
Editorial \\ Prognostic ability of a panel of immunohistochemistry markers - retailoring of an 'old solution'
}

\author{
Donal J Brennan and William M Gallagher
}

UCD School of Biomolecular and Biomedical Science, UCD Conway Institute, University College Dublin, Belfield, Dublin 4, Ireland

Corresponding author: William M Gallagher, william.gallagher@ucd.ie

Published: 25 February 2008

Breast Cancer Research 2008, 10:102 (doi:10.1186/bcr1854)

This article is online at http://breast-cancer-research.com/content/10/1/102

(c) 2008 BioMed Central Ltd

See related research article by Crabb et al., http://breast-cancer-research.com/content/10/1/R6

\begin{abstract}
An urgent requirement exists for new prognostic and predictive assays in breast cancer. Despite the development of highthroughput technologies such as DNA microarrays, it would now appear that immunohistochemistry $(\mathrm{IHC})$ may play an increasingly important role in the clinical management of breast cancer. In this editorial, the authors discuss the potential prognostic ability of a panel of IHC markers, and question whether this well-established assay technology may in fact allow for improved prognostic and predictive tests in breast cancer.
\end{abstract}

Breast cancer, like many other types of cancer, is a complex heterogeneous disease controlled by a multitude of genetic and epigenetic alterations. It is now a well-recognised fact that conventional prognostic and predictive markers fail to capture this heterogeneity in the clinical setting. In this issue of Breast Cancer Research, Crabb and colleagues [1] describe a novel eight-marker, immunohistochemistry (IHC)based, prognostic test for patients with advanced lymphnode-positive (more than four positive lymph nodes) disease. The eight markers included in the analysis were estrogen receptor (ER), progesterone receptor (PR), Ki-67, Her2, epidermal growth factor receptor, cytokeratin 5/6, p53 and carbonic anhydrase IX (CA IX). The group used a selected set of tissue microarrays (TMAs) constructed from a wellestablished, population-based cohort $(n=4,444)$ from British Columbia to both test and validate their approach. Multivariate analysis of all tumours with at least four positive lymph nodes $(n=602)$ revealed that tumour size, percentage of positive lymph nodes, PR, Ki-67 and CA IX were significant predictors of recurrence-free survival. The group randomly selected test and validation sets within their cohort and used a novel score to stratify patients into three groups, based on the expression of the eight markers. Interestingly, whereas they had excellent results in their test set, the prognostic strength of the eight-marker test was markedly reduced in the validation set. The paper raises important issues.

Our understanding of the underlying molecular mechanisms in breast cancer has increased exponentially over the last two decades. Technologies such as DNA microarrays, mass spectrometry-based proteomics and metabolomics have revolutionised translational research over the last decade. The application of DNA microarray technology, in particular, has led to an ever-growing comprehension of the complexity of the underlying pathophysiological pathways and interactions within a breast tumour [2]. There is no doubt that gene expression studies are an excellent platform for discovery; however, it is debatable whether they will ever be clinically applicable due to their prohibitive cost, reliance on frozen tissue and the advanced technical expertise required to use the technology. TMAs are an ideal platform for developing an IHC-based surrogate of a gene expression profile and enabling groups to reduce an assay to clinical utility [3].

The development of IHC was initially credited to Coons and Jones [4], who established an immunofluorescent technique for the detection of bacteria. It was not until the late 1970s that IHC became a standard tool in diagnostic pathology. In more recent times, IHC has been used to predict response to therapy in patients with cancer (for example, the measurement of ER and Her2 expression in relation to tamoxifen and trastuzumab treatment, respectively). With the advent of TMAs and high-throughput pathology, new demands have been placed on the quality, reproducibility and accuracy of IHC assays, many of which have been addressed and led to the development of $\mathrm{IHC}$ surrogates.

CA IX = carbonic anhydrase IX; ER = estrogen receptor; HPA = Human Protein Atlas; IHC = immunohistochemistry; $P R=$ progesterone receptor; $\mathrm{TMA}=$ tissue microarray. 
It is quite plausible that IHC surrogates may be a more appropriate clinical assay than gene expression-based platforms in the future. As demonstrated by Nielsen and colleagues [5] and Carey and colleagues [6], it is possible to identify molecular subgroups (Luminal A, Luminal B, Basal and Her2) using a small number of $\mathrm{IHC}$ markers. Likewise, Ring and colleagues [7] have reported on a novel panel of five antibodies which can predict outcome in ER-positive tumours. Additionally, it has recently been demonstrated that a number of the different prognostic gene expression signatures developed over the last 5 years showed significant agreement in outcome prediction in a single cohort of patients [8]. As there was a minimal overlap of genes used in each of the prognostic signatures, these findings would suggest that they are all tracking a similar phenotype, which may be possible to identify using a panel of IHC markers in the future.

Traditionally, the main obstacle to IHC has been the lack of high-quality specific antibodies. However, the development of high-throughput antibody-based proteomic resources promises to help overcome this obstacle. Recently, a comprehensive atlas of human protein expression patterns has been generated through the Human Protein Atlas (HPA) program $[9,10]$. At present, more than 3,000 antibodies (corresponding to more than 2,600 different human proteins) have been screened on TMAs comprised of 48 types of normal tissues, 216 human tumours representing the 20 most common forms of human cancer and 47 cell lines [11,12]. It is believed that resources such as the HPA will herald a new era for IHC-based diagnostic, prognostic and predictive tests.

Another issue raised by Crabb and colleagues is that of biomarker validation. One of the disappointing aspects of the post-genomic era is that while a plethora of putative biomarkers have undergone preliminary clinical evaluations, only a small minority have received regulatory approval for clinical use. This apparent bottleneck in transfer from biomarker discovery to clinical application is primarily due to a lack of rigorous validation of emerging biomarkers. In 2004, a standard template, called the Standards for Reporting of Diagnostic Accuracy (STARD) initiative, was developed to encourage the use of standards for the reporting of diagnostic accuracy for new tests [13]. Unfortunately, many of the studies published regarding new candidate biomarkers fail to meet these standards. In particular, the studies are often performed on small retrospective cohorts and lack power; additionally, many biomarker studies fail to include an independent validation stage, whereby the biomarker is evaluated using a second independent cohort of patients. This, however, can be a time-consuming process and the approach taken by Crabb and colleagues, in which they split their cohort into test and validation sets and saw a marked difference in the prognostic strength of their IHC panel between the test and validation sets, is worth noting. Despite these findings, it would be beneficial to examine the eightmarker prognostic test in an independent cohort, particularly given the fact that only half of the patients in the study by Crabb and colleagues received adjuvant chemotherapy. Current clinical guidelines would advocate adjuvant chemotherapy for all patients with advanced nodal disease [14]. Interestingly, Crabb and colleagues demonstrated that $76 \%$ of patients who scored highest on their prognostic test, and thus had a significantly worse prognosis, had received chemotherapy. This would suggest that the eight-marker test warrants investigation in a cohort in which all patients received chemotherapy and may provide interesting data regarding resistance to adjuvant chemotherapy.

\section{Competing interests}

The authors declare that they have no competing interests.

\section{References}

1. Crabb SJ, Bajdik CD, Leung S, Speers $\mathrm{CH}$, Kennecke $\mathrm{H}$, Huntsman DG, Gelmon KA: Can clinically relevant prognostic subsets of breast cancer patients with four or more involved axillary lymph nodes be identified through immunohistochemical biomarkers? A tissue microarray feasibility study. Breast Cancer Res 2008, 10:R6.

2. Brennan DJ, O'Brien SL, Fagan A, Culhane AC, Higgins DG, Duffy MJ, Gallagher WM: Application of DNA microarray technology in determining breast cancer prognosis and therapeutic response. Expert Opin Biol Ther 2005, 5:1069-1083.

3. Brennan DJ, Kelly C, Rexhepaj E, Dervan PA, Duffy MJ, Gallagher WM: Contribution of DNA and tissue microarray technology to the identification and validation of biomarkers and personalised medicine in breast cancer. Cancer Genomics and Proteomics 2007, 4:3-16.

4. Coons AC, Jones RN: Immunological properties of an antibody containing a fluorescent group. Proc Soc Exp Biol Med 1941, 47:200-202.

5. Nielsen TO, Hsu FD, Jensen K, Cheang M, Karaca G, Hu Z, Hernandez-Boussard T, Livasy C, Cowan D, Dressler L, Akslen LA Ragaz J, Gown AM, Gilks CB, van de Rijn M, Perou CM: Immunohistochemical and clinical characterization of the basal-like subtype of invasive breast carcinoma. Clin Cancer Res 2004, 10:5367-5374.

6. Carey LA, Perou CM, Livasy CA, Dressler LG, Cowan D, Conway K, Karaca G, Troester MA, Tse CK, Edmiston S, Deming SL, Geradts J, Cheang MC, Nielsen TO, Moorman PG, Earp HS, Millikan RC: Race, breast cancer subtypes, and survival in the Carolina Breast Cancer Study. JAMA 2006, 295:2492-2502.

7. Ring BZ, Seitz RS, Beck R, Shasteen WJ, Tarr SM, Cheang MC, Yoder BJ, Budd GT, Nielsen TO, Hicks DG, Estopinal NC, Ross DT: Novel prognostic immunohistochemical biomarker panel for estrogen receptor-positive breast cancer. J Clin Oncol 2006, 24:3039-3047.

8. Fan C, Oh DS, Wessels L, Weigelt B, Nuyten DS, Nobel AB, van't Veer $L$, Perou CM: Concordance among gene-expressionbased predictors for breast cancer. N Engl J Med 2006, 355: 560-569.

9. Human Protein Atlas homepage [http://www.proteinatlas.org].

10. Uhlén $M$, Björling $E$, Agaton $C$, Szigyarto $C A$, Amini B, Andersen $\mathrm{E}$, Andersson AC, Angelidou P, Asplund A, Asplund C, Berglund L, Bergström K, Brumer H, Cerjan D, Ekström M, Elobeid A, Eriksson C, Fagerberg L, Falk R, Fall J, Forsberg M, Björklund MG, Gumbel K, Halimi A, Hallin I, Hamsten C, Hansson M, Hedhammar $\mathrm{M}$, Hercules $\mathrm{G}$, Kampf $\mathrm{C}$, et al:: A human protein atlas for normal and cancer tissues based on antibody proteomics. Mol Cell Proteomics 2005, 4:1920-1932.

11. Kampf C, Andersson AC, Wester K, Bjorling E, Uhlen M, Ponten $\mathrm{F}$ : Antibody-based tissue profiling as a tool for clinical proteomics. Clinical Proteomics 2004, 1:285-299.

12. Andersson $A C$, Stromberg $S$, Backvall $H$, Kampf $C$, Uhlen $M$, Wester K, Ponten F: Analysis of protein expression in cell microarrays: a tool for antibody-based proteomics. J Histochem Cytochem 2006, 54:1413-1423.

13. Bossuyt PM, Reitsma JB, Bruns DE, Gatsonis CA, Glasziou PP, 
Irwig LM, Moher D, Rennie D, de Vet HC, Lijmer JG: The STARD statement for reporting studies of diagnostic accuracy: explanation and elaboration. Ann Intern Med 2003, 138:W1-12.

14. Goldhirsch A, Wood WC, Gelber RD, Coates AS, Thurlimann B, Senn $\mathrm{HJ}$ : Meeting highlights: updated international expert consensus on the primary therapy of early breast cancer. $J$ Clin Oncol 2003, 21:3357-3365. 